\title{
Determination of methanol and ethanol concentrations in local and foreign alcoholic drinks and food products (Banku, Ga kenkey, Fante kenkey and Hausa koko) in Ghana
}

\author{
Samuel Kofi Tulashie ${ }^{1 *}$, Amponsah Preko Appiah', George Dzidefo Torku', Albert Yaw Darko² \\ and Augustus Wiredu²
}

\begin{abstract}
Background: It is believed that higher methanol content may be present in some alcoholic drinks produced by traditional distilleries or some alcohol brewing companies. As a result of this, there could be a higher risk of methanol concentration in products. Therefore, this research focused on quantifying the amount of methanol in some fermented foods and alcoholic drinks by Gas Chromatography. The method was validated for limit of detection, limit of quantification, and recovery.

Results: The results showed some level of methanol in some of the studied local and foreign alcoholic drinks between the ranges of $0.003-0.161 \%$ Vol. whereas no methanol was observed in any of the analyzed food products.

Conclusions: The results showed that the levels of methanol observed in the analyzed drinks do not pose any health threat to the human body when consumed, contrary to the general assumptions that it does. However, the normal alcohol health risk associated with high consumption still remains a problem.
\end{abstract}

Keywords: Akpeteshie, Methanol, Hausa koko, Kenkey, Banku

\section{Background}

Alcohol can be described as a psychoactive drug which has extensive applications in both industries and households. Alcohol can be produced locally or industrially in large or small quantities based on the available resources across the world (ePURE, 2017). Most farmers engage in alcohol production not only as a means to generate income to earn a living, but also due to the high level of demand and use in diverse ways by consumers across the globe (Glithero et al. 2013). The sources of raw materials for the production of alcohol can be obtained from fruits, cassava, palm wine, sugar cane, etc. The basic method for the production of alcohol is by

\footnotetext{
* Correspondence: stulashie@ucc.edu.gh

${ }^{1}$ School of Physical Sciences, Department of Chemistry, Industrial Chemistry

Section, University of Cape Coast, Cape Coast, Ghana

Full list of author information is available at the end of the article
}

fermentation or decomposition and simple distillation (Manoel, Teresa, José, \& Cássia, 2014). It is assumed that most traditional alcohol manufacturers are ignorant about the basic chemical compositions of the alcohol they produce and hence may end up producing alcoholic drinks with higher methanol content and other potential health threatening components (Jurgen, et al., 2014). Dangerous chemical compositions such as lead and methanol present in alcohol pose a threat to human health. Ethanol and methanol have similar physicochemical properties and are present as by-products after distillation (Jurgen, Fotis, \& Dirk, 2010). According to World Health Organization (WHO), the harmful use of alcohol causes an estimated 2.5 million deaths every year, of which a significant proportion occurs in the young. There is also emerging evidence that the harmful use of alcohol contributes to the health burden caused 
by communicable diseases such as tuberculosis and HIV/AIDS (WHO, 2004).

The quality of alcoholic beverages in Ghana (especially the traditionally brewed) has been a source of concern for some time (Luginaah and Dakubo 2003). It is believed that methanol may be generated in alcoholic drinks during the fermentation process. The lack of proper fermentation and distillation techniques by traditional or artisanal distilleries and some commercial operators may be a factor to high risk of methanol content in the products (Elijah 2016). Also, the complications and chronic diseases or ill health such as blindness, dizziness, respiratory diseases etc., associated with drunkenness suggested that there may be the presence of methanol and other toxic substance in the drink that affects the health of the people (Lachenmeier 2007). Methanol is a chemical solvent, widely used in products such as paints, gasoline, and photocopying fluid. Methanol occurs naturally in food, notably in fresh fruits, vegetables and their juices. It occurs as free methanol, methyl esters of fatty acids or methoxy groups on polysaccharides such as pectin from which it can be released by digestion. Pectin is broken down during digestion in the colon, from where methanol can be absorbed. This means that the potential methanol intake from the diet is higher than analysis of the free methanol content of individual foodstuffs (Lang et al. 2006). The ingestion of as little as $10 \mathrm{ml}$ of methanol can cause permanent blindness and $30 \mathrm{ml}$ can be fatal (Lal et al. 2001). Methanol is metabolized by alcohol dehydrogenase that converts it to formaldehyde and finally to formic acid, the metabolite responsible for its toxicity. Folate is necessary to metabolize and excrete formic acid (Lal et al. 2001). Observed human oral lethal dosage of methanol via ingestion ranges from 15 to $250 \mathrm{~g}$ (Gibel et al. 1969).

This work focuses on quantifying the concentrations of methanol in both local and foreign alcoholic drinks and some fermented food products (Banku, Ga kenkey, Fante kenkey and Hausa koko) in Ghana by using Gas Chromatography with thermal conductivity detector (GC-TCD) as an analytical method.

\section{Methods}

\section{Sampling}

Twenty samples of most commonly used local and foreign alcoholic beverages in Ghana were randomly purchased from various shops in the Greater Accra and Volta regions of Ghana. The selected alcoholic beverages were in the categories of spirits, wines and herbal bitters. The raw materials for the foreign beverages differed from one another, but were mostly cereals and fruits as well as selected herbs which were fermented and distilled industrially. However, all samples of the locally made spirit (Akpeteshie) were produced by artisanal (traditional) brewery. The selected local food products (Banku, Ga kenkey, Fante kenkey and Hausa koko) were purchased from the University of Cape Coast, UCC (science market) in the central region of Ghana. These food products with the exception of Hausa koko were all produced from fermented corn dough. Hausa koko on the other hand was produced from milled millet grains that were allowed to stand and ferment for some days. The purchased samples were then given unique serial numbers.

\section{Reagents}

Analytical grade reagents were utilized. Standard reference solutions of Methanol, Isopropyl alcohol and distilled water were used for the development of the GC calibration curve for this work.

\section{Sample preparation}

$2.5 \mathrm{ml}$ of each alcoholic beverage sample was measured into a measuring cylinder and topped up with de-ionized water to the mark. The food samples were prepared by measuring the mass, $154.75 \mathrm{~g}, 210.00 \mathrm{~g}, 214.91 \mathrm{~g}$ and $245.55 \mathrm{~g}$ of Banku, Hausa koko, Ga kenkey and Fante kenkey respectively and were dissolved separately in de-ionized water. Filtration was done to obtain a clear solution for GC analyses. A portion of the prepared sample was then used for the GC analysis.

Table 1 Detailed description of the operating conditions of the GC

\begin{tabular}{ll}
\hline Parameter & Value \\
\hline Injector temperature set point & $120^{\circ} \mathrm{C}$ \\
Injector flow rate & $21 \mathrm{ml} / \mathrm{min}$ \\
Type of column & Packed Column \\
FFAP & $15 \%$ Chromosorb which \\
& is highly polar \\
Column flow rate & $20 \mathrm{ml} / \mathrm{min}$ \\
Initial oven temperature & $60{ }^{\circ} \mathrm{C}$ on hold for 5 min \\
Final oven temperature & $120^{\circ} \mathrm{C}$ on hold for 5 min \\
Temperature increases interval & at $10^{\circ} \mathrm{C} / \mathrm{min}$ interval \\
Detector temperature & $250{ }^{\circ} \mathrm{C}$ \\
Reference flow rate & $50 \mathrm{ml}$ \\
Limit Of detection (Methanol) & $1.43 \times 10^{-4} \% \mathrm{Vol}$ \\
Limit of detection (Ethanol) & $1.54 \times 10^{-4} \% \mathrm{Vol}$ \\
Limit of quantification (Methanol) & $4.77 \times 10^{-4} \% \mathrm{Vol}$ \\
Limit of quantification (Ethanol) & $5.12 \times 10^{-4} \% \mathrm{Vol}$ \\
Recovery Range \% & $80 \%-100 \%$ \\
\hline
\end{tabular}


Table 2 Summary of the mean concentrations of methanol and ethanol in the analyzed alcoholic drinks

\begin{tabular}{|c|c|c|c|c|c|c|}
\hline Drinking spot & Location & Alcohol type & Origin & Code & Methanol (\%vol) & Ethanol (\%vol) \\
\hline Maxi spot & Mafi Asiekpe & Spirit & Local & S2 & - & 37 \\
\hline Home & Osu-Nyaneba Est. & Wine & Foreign & S3 & 0.009 & 12 \\
\hline Home & Osu- Nyaneba Est. & Whisky/spirit & Foreign & S4 & 0.007 & 40 \\
\hline Home & Osu- Nyaneba Est. & Wine & Foreign & S5 & 0.007 & 17 \\
\hline Maxi spot & Mafi Asiekpe & Bitters/spirit & Local & S6 & & 40 \\
\hline Distillation point & Mafi Mankukope & Akpeteshie/spirit & Local & S7 & 0.052 & 45 \\
\hline Maxi spot & Mafi Asiekpe & bitters/spirit & Local & S8 & - & 29 \\
\hline Maxi spot & Mafi Asiekpe & bitters/spirit, med. Alcohol & Local & S9 & - & 32 \\
\hline Home & Osu-Nyaneba Est. & Wine & Foreign & S10 & 0.003 & 8 \\
\hline Maxi spot & Mafi Asiekpe & dry gin/spirit & Local & S11 & - & 37 \\
\hline Desiadenyo spot & Mafi Asiekpe & Spirit & Local & S12 & - & 31 \\
\hline Desiadenyo spot & Mafi Asiekpe & spirit, med. Alcohol & Local & $\mathrm{S} 13$ & - & 37 \\
\hline Desiadenyo spot & Mafi Asiekpe & bitters/spirit & Local & S14 & 0.063 & 38 \\
\hline Maxi spot & Mafi Asiekpe & spirit, med. Alcohol & Local & S15 & 0.112 & 22 \\
\hline TOR Bush Canteen & Tema-Accra & Akpeteshie/spirit & Local & S16 & - & 36 \\
\hline Original Auntie BB & Osu-Nyaneba Est. & Akpeteshie/spirit & Local & S17 & 0.126 & 42 \\
\hline VYKISS spot & Osu-Ako-Adjei & spirit, med. Alcohol & Local & S18 & 0.142 & 43 \\
\hline Auntie Afi's Enterprise & Osu-Ako-Adjei & Akpeteshie/spirit & Local & S19 & 0.141 & 39 \\
\hline Jomens Enterprise & Osu-Ako-Adjei & Akpeteshie/spirit & Local & S20 & 0.161 & 39 \\
\hline
\end{tabular}

Note that the brand names of these alcoholic beverages have been withheld for security reasons

\section{Instrumentation}

For the quantification of the methanol and ethanol content in the prepared samples, a GC model of Agilent US 6890 N Series (California, USA) equipped with a thermal conductivity detector purchased from Agilent Technology was used. The GC was calibrated using prepared mixtures of analytical grade ethanol, methanol and water. A $(3.0 \mu \mathrm{l})$ portion of each prepared sample was introduced into the injector port and the analysis was carried out in operation conditions stated below in Table 1 .

\section{Results and discussion}

The Table 2 depicts a summary of the mean concentrations of two replicates each for ethanol and methanol analyzed in the alcoholic drinks in each case.

Table 2 shows the variations in the concentrations of methanol and ethanol of the various samples analyzed. Ethanol concentration of the samples ranged between 7 and $46 \%$ whereas that of methanol ranged from "not detectable" to $0.161 \%$. Akpeteshie recorded the highest amount of methanol and ethanol concentrations among the analyzed samples in all cases. From Table 2, it was also observed that eight of the alcoholic drinks (sample codes; S2, S6, S8, S9, S11, S12, S13 and S16) recorded no amount of methanol concentration whereas twelve of the analyzed samples (sample codes; S3, S4, S5, S7, S10, S14, S15, S17, S18, S19 and S20) showed traces of methanol at different concentrations. Among the samples that tested positive for methanol content, sample S10 (a foreign wine) recorded the lowest amount of methanol concentration (0.003\%) while sample S20 (Akpeteshie) showed the highest methanol concentration $(0.161 \%)$. The results show that low amounts of methanol were recorded in the foreign drinks as compared to the local drinks.

Whereas WHO reported oral lethal dose of methanol between $0.3-1 \mathrm{~g} / \mathrm{kg}$ (20 to $60 \mathrm{~g}$ or $25-75 \mathrm{ml} /$ person in a $60 \mathrm{~kg}$ adult) (WHO 1997), a 0.161\% methanol level as seen in the analysis implies that $1.61 \mathrm{ml}$ of methanol may be realized in $1 \mathrm{~L}$ of the alcoholic drink (Akpeteshie) and hence possesses no potential health threat

Table 3 Ethanol and methanol concentration in the analyzed local fermented food products

\begin{tabular}{|c|c|c|c|c|}
\hline Food vendor & Location & Sample name & Methanol(\%vol) & Ethanol (\%vol) \\
\hline \multirow[t]{4}{*}{ Emmanuel chop bar } & Science market, UCC & Banku extract & - & 0.0297 \\
\hline & Science market, UCC & Ga Kenkey extract & - & 0.007 \\
\hline & Market entrance, UCC & Hausa koko extract & - & 0.0141 \\
\hline & Amamoma & Fante kenkey extract & - & 0.139 \\
\hline
\end{tabular}


when consumed. However, the oral lethal dose of ethanol had been reported in the range 5 to $8 \mathrm{~g} / \mathrm{kg}$. Thus, for a $60 \mathrm{~kg}$ adult, $300 \mathrm{~g}(384 \mathrm{ml})$ of ethanol can be fatal (Alcohol.org.nz), therefore, ethanol concentrations of $39 \%$ and above as seen in some of the analyzed drinks (S4, S6, S7, S17, S18, S19 and S20) implies that at least $390 \mathrm{ml}$ of ethanol is contained in $1 \mathrm{~L}$ of the alcoholic drink and may all the same cause higher health risks when consumed excessively or without care.

Table 3 shows a summary of methanol and ethanol concentrations found in the fermented food products.

All these food products were produced from corn dough with the exception of Hausa koko, which was produced from millet grains. To make corn into dough, it was first soaked in water for about 3 days and then drained off the water after which it was milled into fine powder. The obtained powder was mixed with a small amount of water and made into dough. The dough was then left for some days to ferment before being used to prepare the desire food product (Ga Kenkey, Fante Kenkey and Banku). The millet grains were also treated in the same way to obtain millet dough from which Hausa koko was produced.

No amount of methanol was observed in the food products. Fante kenkey recorded the highest amount of ethanol concentration. The concentration of ethanol in Ga kenkey was insignificant as compared to that of Fante kenkey.

\section{Conclusions}

Determination and quantification of methanol and ethanol concentration in alcoholic drinks and some local fermented food products showed that some amounts of methanol between the ranges of "not detectable" to $0.161 \%$ were found in most of the alcoholic drinks that were investigated, but were however below the minimum oral lethal dose $0.3-1 \mathrm{~g} / \mathrm{kg}$ (20 to $60 \mathrm{~g}$ or $25-$ $75 \mathrm{ml} /$ person in a $60 \mathrm{~kg}$ adult). The food products recorded no amount of methanol but contained small quantities of ethanol between the ranges of 0.006$0.140 \%$ which are not harmful to the body. The concentration of ethanol in most of the alcoholic drinks was below the suggested lethal dose of 5 to $8 \mathrm{~g} / \mathrm{kg}$ for a $60 \mathrm{~kg}$ adult, $300 \mathrm{~g}(384 \mathrm{ml})$ of ethanol. However, Akpeteshie seemed to contain $40-45 \% \mathrm{Vol}$ of ethanol implying that at least $400 \mathrm{ml}$ of ethanol is contained in $1 \mathrm{~L}$ of the drink and hence may cause higher health risks when consumed excessively or without care.

This research work suggests that despite the fact that methanol was found to be present in most of the analyzed alcoholic drinks, the levels observed do not pose any health threat to the human body when consumed, contrary to the general assumptions that it does. However, the normal alcohol health risk associated with high consumption still remains a problem and therefore, it is recommended that typical alcohol policy responses such as increases of sales prices via taxation especially for the locally made spirit (Akpeteshie) which appears to be cheaper on the market as well as restrictions of availability of such beverages be implemented, alongside sensitization campaigns to educate the national populace on the dangers of excess alcohol intake.

\section{Additional files}

Additional file 1: Validation data. (XLSX $32 \mathrm{~kb})$

Additional file 2: Chromatograms of the analyzed food and drink samples. (PDF 8503 kb)

\section{Acknowledgements}

The authors are grateful to the Tema Oil Refinery and University of Cape Coast, Ghana for availing their laboratories for the experimental work. We also thank Mr. Francis Kotoka for his suggestions towards this manuscript.

Funding

Not applicable.

\section{Availability of data and materials}

All the data, including chromatograms with respect to measurements made in this manuscript are available in the manuscript and as Additional files 1 and 2 to support this manuscript.

\section{Authors' contributions}

All the authors contributed significantly to this manuscript. SKT was the chief supervisor of the entire process from the experimental work to the writing of the manuscript. AYD and AW did the laboratory analyses/experimental work of the local and foreign drinks respectively. APA and GDT did all the sampling, undertook the experimental work/laboratory analyses of the local fermented food products, and drafted the entire manuscript. All authors read and approved the final manuscript.

Ethics approval and consent to participate

Not applicable.

Consent for publication

All the authors have consented to the publication of this manuscript.

\section{Competing interests}

The authors declare that they have no competing interests.

\section{Publisher's Note}

Springer Nature remains neutral with regard to jurisdictional claims in published maps and institutional affiliations.

\section{Author details}

${ }^{1}$ School of Physical Sciences, Department of Chemistry, Industrial Chemistry Section, University of Cape Coast, Cape Coast, Ghana. ${ }^{2}$ Tema Oil Refinery,

Quality Control Department, Heavy Industrial Area, P. O. Box Co 599, Tema, Ghana.

Received: 28 June 2017 Accepted: 5 October 2017

Published online: 24 October 2017

\section{References}

Elijah IO (2016) Methanol contamination in traditionally fermented alcoholic beverages: the microbial dimension. Springerplus.

ePURE. (2017). About ethanol. Retrieved august 27th, 2017, from ePURE European Renewable Ethanol: http://epure.org/about-ethanol/

Gibel W, Wildner GP, Lohs K. Experimental studies on hepatotoxic effect of higher alcohols (fusel oil). Z Gastroenterologie. 1969;7:108-13. 
Glithero NJ, Ramsden SJ, Wilson P (2013) Barriers and incentives to the production of bioethanol from cereal straw: a farm business perspective. ELSEVIER - Energy Policy, 161-171.

Jurgen R, Fotis K, Dirk WL. Unrecorded consumption, quality of alcohol and health consequences. Drug and Alcohol Review - APSAD. 2010:426-36.

Jurgen R, Shalini K, Elisabeth L, Maximilien XR, Andriy VS, Kevin DS, et al. A systematic review of the epidemiology of unrecorded alcohol consumption and the chemical composition of unrecorded alcohol. Addiction. 2014:880-93.

Lachenmeier DW. Rapid quality control of spirit drinks and beer using multivariate data analysis of Fourier transform infrared spectra. Food Chem. 2007;101:825-32

Lal J, Kumar CV, Suresh MV, Indira M, Vijayammal PL. Effect of exposure to country liquor (toddy) during gestation on lipid metabolism in rats. Plant Foods Hum Nutr. 2001;56:133-43.

Lang K, Vali M, Szucs S, Adany R, McKee M. The composition of surrogate and illegal alcohol products in Estonia. Alcohol. 2006:41:446-50.

Luginaah, I., \& Dakubo, C. Consumption and impacts of local brewed alcohol (akpeteshie) in the Upper West Region of Ghana: a public health tragedy. Soc Sci Med. 2003:1747-1760

Manoel, R. L., Teresa, L. V., José, C. F., \& Cássia, R. L. (2014). OTHER RAW MATERIALS FOR PRODUCING ETHANOL. São Paulo, Brazil.

WHO. The World Health Report :2004; Changing History. Geneva, Switzerland: World Health Organization; 2004

World Health Organization. International program on chemical safety, environmental health criteria no. 196: methanol. Geneva: World Health Organization; 1997.

\section{Submit your manuscript to a SpringerOpen ${ }^{\circ}$ journal and benefit from:}

- Convenient online submission

- Rigorous peer review

- Open access: articles freely available online

- High visibility within the field

- Retaining the copyright to your article

Submit your next manuscript at $>$ springeropen.com 